\title{
A questão produtiva nas Reservas Extrativistas
}

\section{Agricultural Production in Extractive Reserves}

Gabriel da Silva Medina - Professor da Universidade Federal de Goiás; pós-doutor em Políticas Ambientais (Imperial College London); doutor em Ciências Naturais (Universidade de Freiburg); mestre em Agriculturas Familiares e Desenvolvimento Sustentável (Universidade Federal do Pará). Email: gabriel.silva.medina@gmail.com.

Claudio Wilson Soares Barbosa - Graduado em Administração Pública, Universidade do Sul de Santa Catarina; mestre em Gestão de Áreas Protegidas da Amazônia pelo Instituto Nacional de Pesquisas da Amazônia. E-mail: claudio.barbosa25@gmail.com

\section{Resumo}

Um dos maiores desafios atuais para o desenvolvimento sustentável da Amazônia éa inclusão produtiva das populações locais, em particular aquelas que vivem em Unidades de Conservação de Uso Sustentável (UC), como as Reservas Extrativistas (Resex). Este artigo descreve os principais sistemas produtivos das populações da Resex Verde para Sempre: manejo de búfalos, extração de madeira e manejo de pesca. Os resultados revelam que esses sistemas tradicionais estão ameaçados pela burocracia governamental, que nega a possibilidade de criação de grandes animais em UCs, mesmo quando a atividade é anterior à criação da unidade; define planos formais de manejo florestal como única opção para o uso comercial das florestas, inclusive com requerimentos inacessíveis para as famílias; e não reconhece os acordos de pesca elaborados pelas comunidades. Sem alternativas para a geração de renda, as famílias estão sendo condenadas à pobreza, à ilegalidade e ao êxodo rural. Tratar da questão produtiva é fundamental para o futuro das Resex no Brasil.

\section{Palavras-chave}

Unidade de conservação. Governança local. Recursos naturais. Amazônia.

\begin{abstract}
One of the greatest challenges for sustainable development in the Amazon is the generation of income by local communities, particularly those living in conservation unities (UC) for sustainable development such as Extractive Reserves (Resex). In this paper we describe the main productive activities carried out by families living in the Resex Verde para Sempre: buffalo ranching, timber extraction and fish management. Results reveal that the development of those traditional activities are hindered by governmental bureaucracy prohibiting buffalo ranching in UC, even considering that the activity precedes the creation of the Resex; requiring formal forest management plans as the only way for commercial use of forests, even aware that the requirements for such plans are non-achievable bylocal families; and not acknowledging local systems for fishing management agreed by community members. Without alternatives for generating income families tend to remain poor, to carry out their activities informally and, ultimately, to leave the Resex. Addressing the issue of income generation by local communities is fundamental for the future development of the Resex in Brazil.
\end{abstract}

\section{Keywords}

Conservation unities. Local governance. Natural resources. Amazon. 


\section{INTRODUÇÃO}

Na Amazônia, um dos grandes desafios enfrentados pelas populações que vivem em Unidades de Conservação (UC), em particular nas Reservas Extrativistas (Resex), é a geração de renda. A dependência dos programas de transferência de renda do governo federal (Bolsa Família e Bolsa Verde) revela a situação de pobreza em que vivem moradores desses espaços protegidos na região (HOMMA; SANTOS, 2015). Tradicionalmente as populações desses territórios têm desenvolvido a agricultura de subsistência e o extrativismo, incluindo a pesca, a extração de madeira e a criação de animais de pequeno e grande portes (MEDINA; BARBOSA, 2015).

A inclusão produtiva para a geração de renda pelas comunidades da Amazônia passa pela valorização e pelo reconhecimento de seu protagonismo, pela construção de propostas produtivas a partir dos conhecimentos, interesses e capacidades locais, pela atuação participativa dos atores externos e pela colaboração do Estado (POKORNY et al., 2010). De acordo com essa concepção, a governança local (ou sistemas locais de produção e gestão) é uma das alternativas mais promissoras, a partir do(a): a) capacidade dos grupos locais em gerenciar estrategicamente seus recursos; b) noção de que propostas e acordos que saiam das comunidades podem ter mais efetividade que a gestão do Estado; c) reconhecimento da importância do Estado como avalista dos sistemas de governança local para garantir sua robustez, principalmente diante de ameaças externas (MEDINA, 2012).

Embora haja evidências da capacidade das comunidades para a governança de recursos naturais locais em todo o mundo (OSTROM, 1999), estudos revelam que as populações locais têm poder político limitado das para fazer valer seus interesses diante de atores externos poderosos (DOVE, 1993). Em muitos casos, o advento da criação das Resex corrobora a correlação de forças desequilibrada, em prejuízo das comunidades locais (BATISTA; SIMONIAN, 2013). Mesmo quando sistemas produtivos locais são estabelecidos, as comunidades enfrentam desafios relacionados ao quadro político-institucional, com o qual precisam interagir para buscar apoio e legitimidade (MUÑOZ et al., 2007).

No caso das Resex, o principal interlocutor das comunidades locais é o Estado brasileiro, representado pelo Instituto Chico Mendes de Conservação da Biodiversidade (ICMBio), que é a autarquia do Ministério do Meio Ambiente (MMA) responsável pelas UC do país. O ICMBio tem caracterizado sua atuação pela ideologia desenvolvimentista, promovida a partir de forte controle da vida das comunidades, com pouca abertura para efetivar sistemas de autogestão dos 
recursos naturais existentes nas Resex (PROST; SANTOS, 2016). A abordagem de comando e controle tem sido privilegiada pelo Estado, mesmo diante de evidências de sua limitada capacidade infraestrutural para implantar políticas de desenvolvimento regional sustentável na Amazônia (OLIVEIRA, 2015).

O conceito de Reserva Extrativista tem suas origens nas lutas dos seringueiros do estado do Acre (ALLEGRET'TI, 2008; GONÇALVES, 2012). Com o advento da Lei 9.985/2000, que cria o Sistema Nacional de Unidade de Conservação (SNUC), Resex passa a ser definida como "área utilizada por populações extrativistas tradicionais, cuja subsistência baseia-se no extrativismo e, complementarmente, na agricultura de subsistência e na criação de animais de pequeno porte, tendo como objetivos básicos proteger os meios de vida e a cultura dessas populações, e assegurar o uso sustentável dos recursos naturais da unidade" (BRASIL, 2000, Art. 18).

Estudos têm apontado percepções diferentes entre populações locais e atores externos sobre a noção de uso sustentável dos recursos naturais e de desenvolvimento sustentável (MENDONÇA; AQUINO, 2014), em muitos casos resultando em conflitos e frustrações das comunidades locais, e comprometendo o desenvolvimento das UCs (PARENTE; BURSZTYN, 2012). A opção pelo comando e controle por parte do Estado tem criado um ambiente de proibições, com ausência de alternativas de desenvolvimento.

Reconhecendo que um dos maiores desafios atuais para o desenvolvimento sustentável da Amazônia é a inclusão produtiva das populações locais, em particular daquelas que vivem em UC de uso sustentável, como as Resex, este trabalho busca: a) identificar os principais conflitos entre os sistemas de produção tradicionais e as normas do órgão gestor das UCs; b) apresentar o funcionamento dos sistemas de produção tradicionais que podem servir de base para a inclusão produtiva das populações locais; c) discutir o papel do Estado e outros atoreschave no apoio ao desenvolvimento rural na Amazônia, em particular no apoio à inclusão produtiva das famílias.

\section{METODOLOGIA}

Este artigo baseia-se em um estudo de caso desenvolvido na maior Resex brasileira, a Reserva Extrativista Verde para Sempre, criada em 2004, em Porto de Moz (PA). Os autores realizaram pesquisa de campo no período de julho de 2010 a agosto de 2013, visando conhecer a situação das comunidades rurais daquele município, como parte das atividades do projeto Governança de Recursos Naturais por Produtores Familiares da Amazônia, relatadas no livro 
"Experiências Produtivas de Agricultores Familiares da Amazônia" (MEDINA; BARBOSA, 2015).

A área rural do município é ocupada há mais de cem anos por populações ribeirinhas que vivem da criação de animais (incluindo gado bubalino e bovino), do uso da floresta e da pesca. A partir de 2004, as famílias, que lutaram pela criação da Resex, passaram a lidar diretamente com o órgão gestor da unidade, buscando garantir a continuidade das suas práticas produtivas tradicionais.

No decorrer da pesquisa, quatro comunidades criadoras de búfalos, famílias de duas comunidades que fazem extração tradicional de madeira e duas comunidades que mantêm acordos de pesca foram assessoradas diretamente com quatro visitas anuais e também em encontros realizados com representantes do poder público para tratar da questão produtiva na Resex. Os sistemas de produção e manejo foram descritos e o esforço das comunidades para o reconhecimento de suas práticas pelo Estado foi acompanhado e relatado nos resultados deste artigo.

\section{RESULTADOS}

\subsection{MANEJO DE BÚFALOS}

\section{Conflitos}

A criação de búfalos tornou-se uma das atividades mais importantes para a população rural de Porto de Moz nas últimas três décadas. Dentre as 107 comunidades e localidades rurais daquela região, em 65 (61\%) há famílias atuando na criação de búfalos (Figura 1). A maior parte dos criadores está concentrada na área de várzea, entre os rios Xingu e Amazonas, ao norte do município. A quantidade de animais por família varia entre 10 e 100 cabeças. Poucos criadores possuem mais de 100 reses, mas têm algumas fazendas com plantéis maiores. A criação de búfalos visa à comercialização da carne e a produção de leite para a fabricação de queijo. O gado vendido para corte funciona como poupança para as famílias e a produção de queijo serve como fonte de renda, que se intercala com a atividade de pesca somente em áreas de várzea; e com a agricultura e extração de madeira em áreas de várzea e terra firme.

A criação da Resex Verde para Sempre em 2004, que inclui a área com criação tradicional de búfalos, suscitou a necessidade de diálogo das famílias e comunidades com órgão gestor de Resex. Esse esforço de diálogo visa garantir a continuidade da criação de búfalos na área da Resex, visto que o SNUC não prevê textualmente a permissão para criação de animais de grande porte nas unidades 
de conservação. A indefinição do governo sobre a manutenção da atividade tem desestimulado as famílias a continuar sua produção, restringido o acesso ao crédito rural, que é essencial para os criadores manterem os investimentos, sobretudo na infraestrutura de marombas (currais suspensos) na época das cheias. que é fundamental para a criação de gado nas áreas de várzea.

Figura 1. Comunidades que criam bubalinos na Resex Verde Para Sempre.

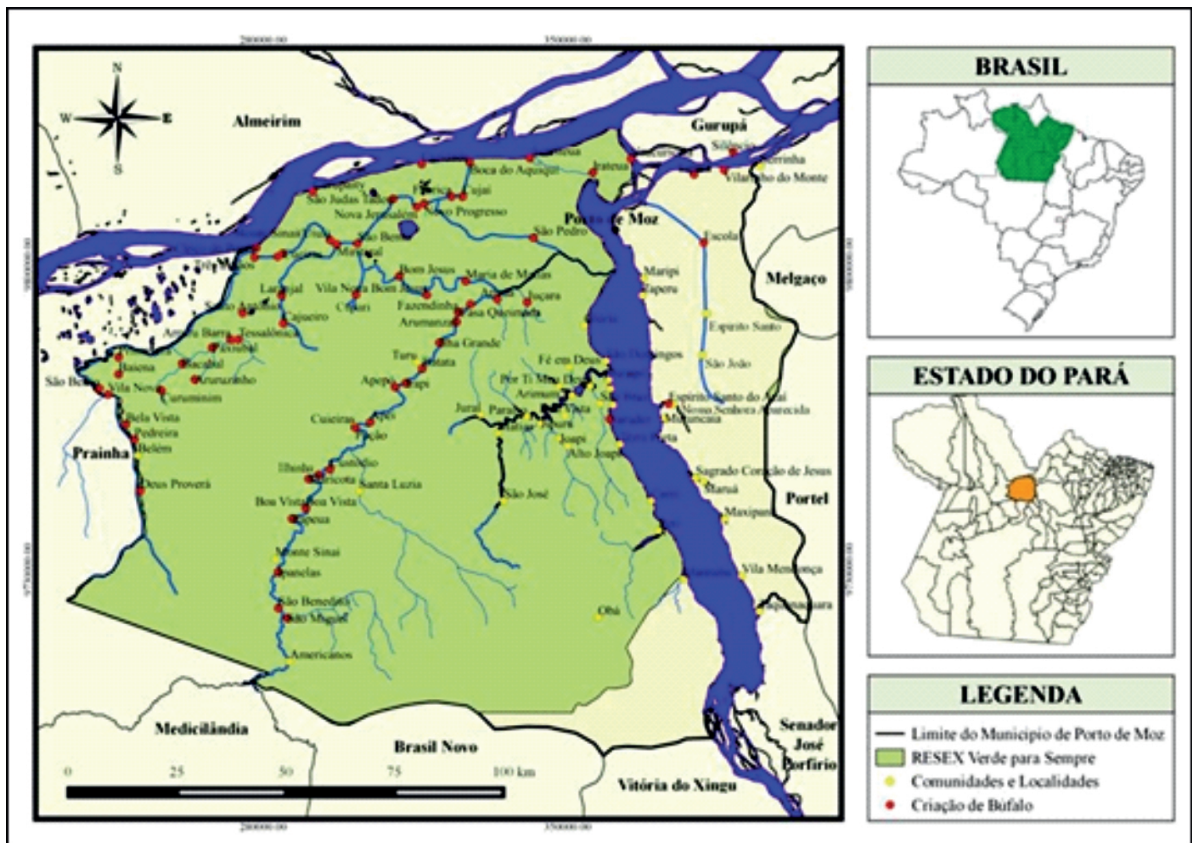

Fonte: trabalho de campo. Elaboração do mapa: Nayra Trindade.

\section{Sistemas de criação}

Os criadores de búfalos da Resex Verde para Sempre utilizam dois principais sistemas de manejo, de acordo com as condições naturais. Nas propriedades localizadas totalmente em áreas de várzea (sem terra firme), os criadores trabalham com manejo do gado em marombas (currais suspensos), com livre acesso às áreas de capim nativo. Já nos terrenos situados nas áreas de transição entre várzea e terra firme utilizam dois tipos de manejo: no período da seca ou das águas baixas, mantêm o gado na várzea, aproveitando os campos naturais; e na época das cheias, quando os pastos naturais são inundados, levam o gado para os pastos plantados na terra firme. Em ambos os casos, a criação de gado depende, fundamentalmente, da disponibilidade das pastagens naturais e da adaptabilidade dos animais. 
A criação do búfalo é organizada em núcleos formados por famílias vinculadas por relações de parentesco e que residem próximas umas das outras. Os animais são tradicionalmente criados soltos e não há cercas dividindo as propriedades. As terras pertencentes a cada um dos criadores são demarcadas por limites naturais, como uma árvore, enseada ou igarapé. Nesse sistema, as relações familiares e a proximidade facilitam o entendimento sobre o uso do espaço comum.

No sistema de criação gado característico das áreas de várzea, às margens dos rios, as famílias constroem casas tipo palafitas e marombas onde os animais descansam e são tratados na época da cheia. Nesse sistema, o principal desafio é garantir a alimentação para o gado no período das cheias, principalmente para os bezerros, que não conseguem nadar grandes distâncias em busca de pastos.

As principais alternativas técnicas desenvolvidas pelos criadores para obterem melhores condições de manejo, considerando as condições ambientais e de investimentos existentes são: 1) Manejo de pastagens naturais, que consiste na rotação de áreas entre o período de cheias e de baixa das águas; 2) Complementação alimentar, com o fornecimento de capim retirado nos campos e nas margens dos rios para bezerros e búfalas que ficam na maromba durante o período pré-parto, que ocorre na época das cheias; 3) preparo da área de recreio, que são quadras (piquetes) na ilharga (próximas) da maromba, para reservar os pastos para a época das cheias. Essas áreas também servem como fontes de alimento, pois fornecem capim aos animais jovens ou podem ser pastejadas com mais facilidade por estarem próximas às marombas.

Nas áreas de transição entre a várzea e a terra firme, tradicionalmente os animais permanecem por cerca de seis meses em cada ambiente. Os animais ficam na área de várzea durante o período de estiagem (de agosto a janeiro), pois os campos naturais propiciam ótimo rendimento de leite, crescimento e engorda do gado, principalmente quando ocorrem as primeiras chuvas de dezembro e o capim rebrota rapidamente. Nas áreas de várzea há predominância das espécies de capim nativo rabo-de-rato, pomunga, arroz bravo e perimembeca às margens dos rios. $\mathrm{Na}$ época das cheias (de fevereiro a julho), os animais são levados para áreas de terra firme, que geralmente são abertas e compostas de capim braquiarão ou quicuio. Quando o criador não possui pasto formado na terra firme, em geral ele arrenda áreas de pastagem para todo o rebanho.

\section{Papel do Estado}

As famílias desenvolveram um sistema de manejo eficiente na criação de gado, considerando as condições locais. Desde a criação da Resex, em 2004, há a promessa de o ICMBio realizar estudos para avaliar os impactos e regulamentar 
a criação de búfalos no interior da UC. A não realização desses estudos e as incertezas das famílias sobre a possibilidade de manutenção da criação na Resex e a suspensão do acesso a qualquer tipo de fomento à atividade por parte do governo, incluindo o crédito Pronaf, estão levando à desestruturação dos sistemas de criação. Portanto, é fundamental que o ICMBio ajuste o SNUC à realidade das populações das Resex que tradicionalmente criam animais de grande porte e, com isso, evite que os bancos suspendam indefinidamente o crédito para investimentos na atividade.

Embora na maioria das Resex se mantenha a criação de animais de grande porte (bovinos ou bubalinos), até agora o MMA tem se mantido omisso em tratar dessa questão à luz da legislação, por entender que há incompatibilidade entre a atividade e o SNUC. No caso da Resex Verde para Sempre, os criadores buscam alternativas a partir da mobilização por meio das associações e, à medida que expõem suas práticas, levam os órgãos e organizações ambientalistas a enfrentar a realidade das UCs de Uso Sustentável na Amazônia.

\section{Extração tradicional de madeira \\ Conflitos}

Os produtos florestais são fundamentais para assegurar os meios de vida tradicionais das populações ribeirinhas da Amazônia, utilizados tanto nas construções ou como fonte de renda via comercialização. Em Porto de Moz, a madeira é o principal produto extraído da floresta e sua exploração comercial passou por quatro ciclos principais:

- De 1970 a 1982 - Produção de madeira lavrada a machado, serrada com o serrotão e extração de madeira em toras, principalmente de espécies de baixa densidade, chamadas de madeira branca;

- De 1982 a 1990 - Entrada de pequenos madeireiros locais trabalhando com bufetes (caminhões velhos) para a retirada de madeira de alta e baixa densidades, em locais mais distantes das vias fluviais;

- De 1990 a 1996 - Introdução de máquinas pesadas pelas grandes empresas e disputa por grandes áreas de floresta para a retirada da madeira;

- De 1996 a 2004 - Elaboração de planos de manejo empresariais, muitas vezes em áreas griladas, e apropriação dos espaços de uso das famílias ou comunidades locais.

A criação da Resex Verde para Sempre encerrou o processo de apropriação das terras e a exploração florestal praticada por grandes empresas madeireiras. Mas grande parte das comunidades localizadas em áreas de terra firme ainda hoje 
complementa o seu sustento com a extração de madeira em toras ou serrada, móveis rústicos, barcos, canoas e remos. A maioria das comunidades produz madeira serrada (esteio, falca, barrote, flechal, viga, tábua e ripa) com o uso de motosserra e fabrica canoas e barcos de pequeno e médio portes para o mercado local e regional. Das 107 comunidades rurais de Porto de Moz (89 dentro da Resex e 18 fora da Resex), em 64 (60\%) há famílias trabalhando com extração de madeira (Figura 2).

Figura 2. Comunidades com famílias que trabalham com extração madeira na Resex Verde Para Sempre.

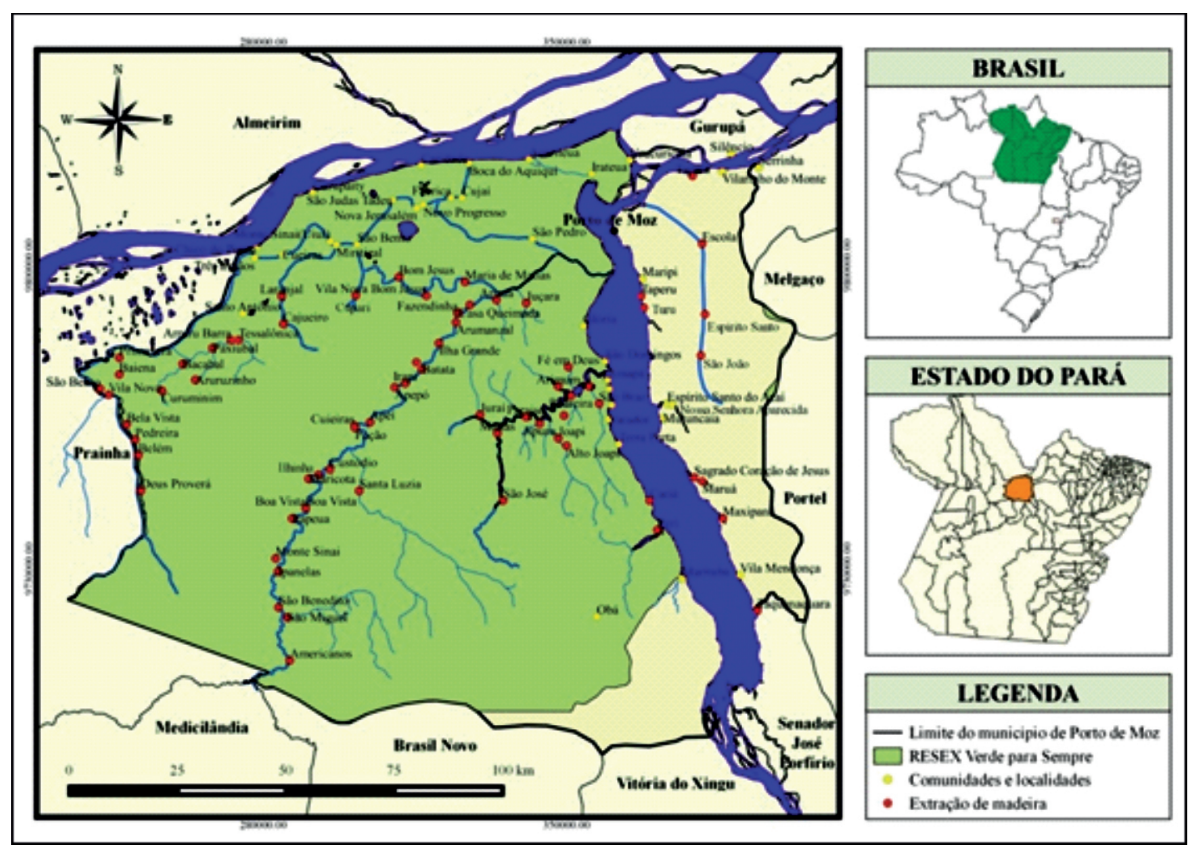

Fonte: trabalho de campo. Elaboração do mapa: Nayra Trindade,

O maior desafio da população rural de Porto de Moz é o reconhecimento legal das suas práticas de uso florestal. As exigências formais do Plano de Manejo Florestal Sustentável (PMFS) são divergentes das práticas tradicionais, dos interesses e da capacidade produtiva das comunidades locais. O PMFS pressupõe a adoção de técnicas que implicam em custos de treinamento, aquisição de equipamentos e a anuência de um engenheiro florestal, onera o processo, além da criação de entidade jurídica e tramitação do processo junto ao órgão ambiental. De acordo com a jurisdição da área, aplicam-se diferentes instrumentos administrativos para regular o acesso e uso dos recursos. Nas Resex, o ICMBio aplica as normas técnicas contidas na Instrução Normativa no 16, de 4 de agosto de 2011. 


\section{Sistema de produção}

A espécie de interesse é definida no ato da encomenda pelo comprador, que determina ao extrativista a espécie, o tamanho e a quantidade de peças, de acordo com o mercado de destino. A madeira retirada pelas famílias serve tanto para a construção de barcos, casas e marombas quanto para a comercialização no mercado local. Itaúba e piquiá são as espécies de maior demanda pela diversidade de usos, em particular na construção de embarcações.

A madeira é retirada principalmente em três tipos de áreas, de acordo com o seu uso:

- Áreas particulares - Os lotes particulares geralmente têm extensão de 100 ha, localizados nas margens dos rios e, embora não haja demarcação espacial estabelecida, são reconhecidos pelos moradores de maneira informal. As famílias exploram os lotes individuais de acordo com suas necessidades, força de trabalho e recursos naturais disponíveis. A exploração dessas áreas tem diminuído expressivamente, em função da redução dos estoques das principais espécies.

- Áreas comunitárias - Mais de 10 comunidades demarcaram áreas comunitárias para resistir à invasão das madeireiras antes da criação da Resex. A exploração ocorre em áreas comuns, normalmente demarcadas nos fundos dos lotes particulares, com uso definido em normas estabelecidas pelo conjunto de moradores de uma determinada comunidade que, em tese, não aceita a entrada de estranhos para explorar madeira. Em geral, essas áreas concentram os maiores estoques de madeira, que são suas reservas para uso futuro ou para elaboração do plano de manejo da comunidade.

- Áreas de livre acesso - Em geral, essas áreas localizam-se nas cabeceiras de igarapés ou em estradas abandonadas por empresas madeireiras, afastadas dos núcleos comunitários e dos lotes individuais. Normalmente são exploradas por grupos específicos, às vezes de diferentes comunidades, embora seja mais comum que famílias da mesma comunidade trabalhem juntas. Esse, a princípio, parece um caso clássico de recursos de livre acesso e, portanto, de difícil governança. Porém, na maioria dos casos, áreas específicas são exploradas por grupos específicos de famílias e podem ser consideradas áreas de uso comum gerenciadas por um grupo mais restrito que uma comunidade.

De modo geral, a escolha da área a ser explorada é feita a partir da espécie desejada, da proximidade das vias de acesso (estrada aberta por empresas e depois abandonadas ou acesso por igarapés) e da ausência de conflito com moradores das proximidades. Para a derrubada das árvores de interesse, geralmente são adotados três critérios básicos: 
- Tamanho da árvore - Rodo (circunferência) acima de $200 \mathrm{~cm}$ e tronco reto (fuste) acima de $5 \mathrm{~m}$ de comprimento e;

- Logística de transporte - Distância entre a localização da árvore e a margem do igarapé, dependendo do meio de transporte disponível;

- Força de trabalho - Para o extrativista que trabalha sozinho, árvores com mais de $400 \mathrm{~cm}$ de circunferência são difíceis de serem posicionadas para serragem, por isso não são preferenciais para o abate.

Os serradores fazem o teste de oco antes da derrubada da árvore, a partir do atrito do facão ou machado no tronco, avaliando o efeito do som emitido. Alguns serradores também fazem o teste através da perfuração com a ponta do sabre da motosserra (em posição horizontal) até o âmago do tronco. Constatando-se que não está oco, a árvore é derrubada na direção em que ficam os galhos mais pesados.

A serragem da madeira é realizada no próprio local da queda da árvore, utilizando-se apenas a motosserra para desdobro. A árvore é serrada em toras, de acordo com o comprimento desejado para as peças. Em seguida, a tora é marcada com uma linha (barbante) envolvida em óleo queimado (óleo lubrificante já usado e com coloração escura). Após esse procedimento, as peças são retiradas e sofrem um segundo corte na parte que fica voltada para baixo da serragem.

O transporte da madeira é feito com o uso de rodado, de tração animal (normalmente búfalos), jerico (microtrator), bufete (caminhão velho) ou manualmente, carregando-se a madeira serrada ou deslocando as toras com o calango. Para as famílias que têm acesso ao bufete ou jerico, as árvores são processadas em locais distantes até $8 \mathrm{~km}$ das margens dos rios ou igarapés que servem como via de escoamento. Para as famílias que usam somente o rodado ou tração animal, as árvores são processadas em áreas, no máximo, a $3 \mathrm{~km}$ de distância das margens dos rios e igarapés.

A abertura dos ramais de acesso para o transporte da madeira é realizada manualmente, utilizando facão ou foice para a roçagem da vegetação rasteira, posterior à derrubada das árvores mais grossas com motosserra, seguida da serragem e destoca das peças. Isso evita desperdício de trabalho, pois haveria perda de tempo e recursos para o produtor, caso tivesse aberto primeiro o ramal e as árvores fossem impróprias para o transporte em peças. Em geral, os ramais são abertos em direção às peças que serão transportadas para as margens dos igarapés (portos de transbordo). Desses portos, as peças são levadas em rabetas ou canoas até o rio principal, de onde são transportadas em embarcações maiores até a cidade ou para outros locais de destino. 


\section{Papel do Estado}

O uso tradicional da floresta para a extração de madeira também tem levado ao enfrentamento entre as comunidades locais e o ICMBio. Essas populações tradicionais exploram a madeira com base na sua capacidade e interesse. Após a criação da Resex, o governo tem sido intransigente na demanda por implantar Planos Formais de Manejo Florestal, com requisitos dissociados das condições de vida das comunidades, o que lhes têm condenado praticamente à informalidade.

Considerando que as famílias não têm condições de arcar com os custos dos PMFS e que as práticas tradicionais atendem aos princípios fundamentais do manejo florestal, o Estado deve reconhecer as práticas tradicionais de extração de madeira e simplificar os procedimentos administrativos. A promoção do manejo florestal comunitário com base nos PMFS ignora que todo o sistema de organização comunitária está associado aos laços de parentesco existentes entre famílias. A forma mais comum de organização da atividade madeireira ocorre entre os membros de uma família ou em núcleos familiares, e não de forma comunitária. A organização em núcleos familiares pode ser estabelecida pela relação de confiança entre os membros das famílias e pela necessidade de agregar um número mínimo de pessoas conhecidas que trabalham em conjunto.

\section{Manejo de Pesca}

\section{Conflitos}

Os Acordos Comunitários de Pesca vêm se constituindo, ao longo dos anos, como uma importante estratégia de gestão coletiva dos recursos pesqueiros na Amazônia. Esses acordos buscam agregar os interesses dos pescadores artesanais que atuam na pesca comercial, dos ribeirinhos que pescam para o consumo e/ou venda e dos órgãos governamentais. Em Porto de Moz, dentre as 107 comunidades e localidades rurais, 22 participam dos sete acordos de pesca ou de convivência existentes no município (Figura 3).

A formulação de "bons" acordos de pesca deve passar por um processo de profunda reflexão e análise sobre os problemas vivenciados pelas comunidades ou grupos que pretendem definir as regras para acesso aos recursos pesqueiros. Esse processo é contínuo e pode demorar vários anos, porém, não precisa, obrigatoriamente, estar documentado ou regulamentado por órgãos do governo. Em muitos casos, as formas de exploração da pesca são constituídas segundo as tradições e os costumes aceitos pelos grupos locais, sem intervenção de atores externos. Esse processo tem apresentado bons resultados quando não há risco de invasão de pescadores de outras localidades, quando a pesca se destina 
à subsistência dos moradores ou quando o volume de pescado capturado é pequeno e, em longo prazo, não afeta os estoques existentes.

Figura 3. Comunidades com acordos de pesca na Resex Verde Para Sempre.

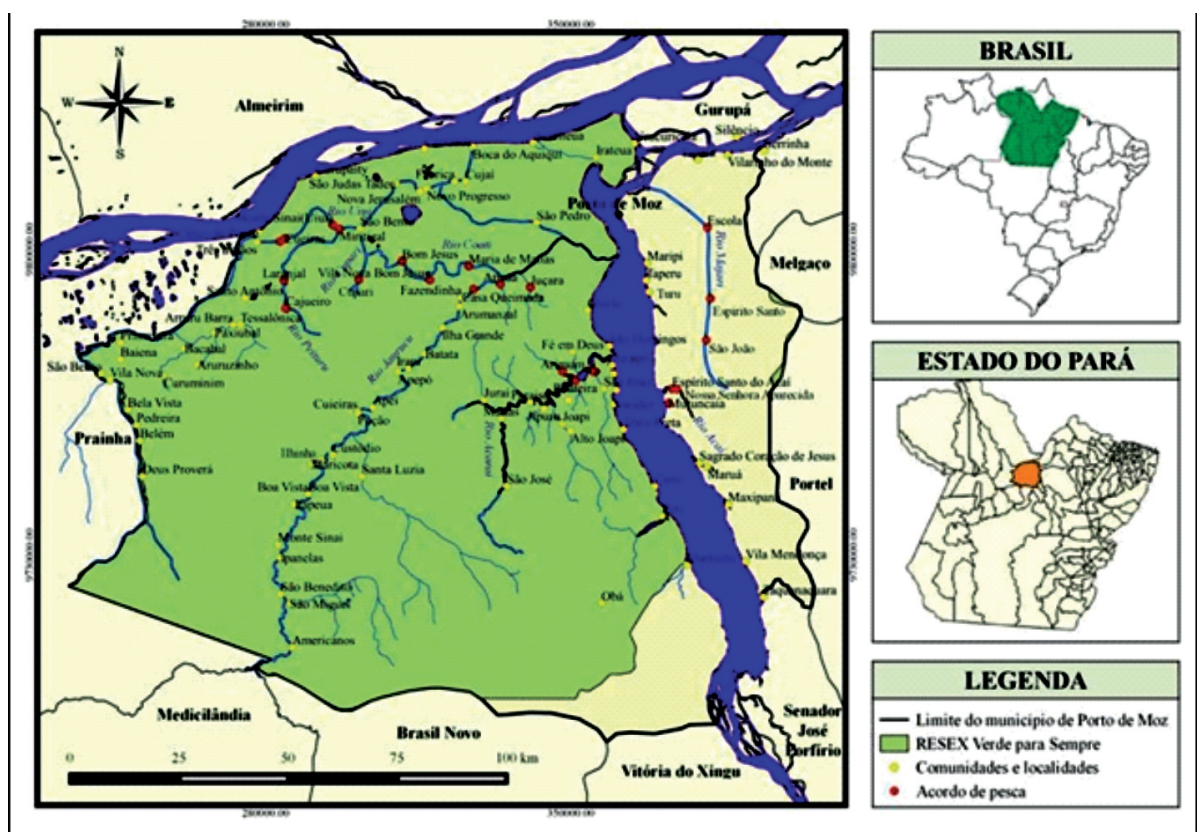

Fonte: Trabalho de campo. Elaboração do mapa: Nayra Trindade.

Contudo, a situação muda quando a pesca tem finalidade comercial. À medida que o mercado demanda maior quantidade de pescado e o preço aumenta, a tendência é que os pescadores intensifiquem a produção. Para isso, eles geralmente adquirem equipamentos com maior capacidade de captura ou prolongam o tempo de trabalho nas atividades de pesca. Isso, aos poucos, vai quebrando as formas tradicionais de uso desses recursos, podendo gerar, em curto prazo, uma crise de escassez das espécies de maior demanda no mercado.

Neste caso, é necessária a elaboração do texto referente à regulamentação das regras estabelecidas pelas famílias visando garantir o maior controle das atividades pesqueiras e assegurar a participação dos órgãos reguladores. Assim, as comunidades que, isoladamente, não conseguem fazer valer as regras do acordo, podem contar com o apoio do poder de polícia do Estado. Para isso, é fundamental que os órgãos governamentais estejam abertos a parcerias com as comunidades e reconheçam esses acordos de pesca.

Em Porto de Moz a Secretaria de Estado de Pesca e Aquicultura do Pará (Sepaq) reconheceu o acordo do Rio Acaí, fortalecendo as comunidades 
e promovendo a gestão eficiente dos recursos. Por outro lado, o ICMBio não aceitou os acordos de pesca dos rios Coati e Cupari, por defender um plano de manejo para toda a UC e não somente para as atividades locais. Os principais argumentos apresentados pelo ICMBio para o não reconhecimento devem-se ao fato de que a competência para elaborar normas é atribuída ao ICMBio e não às comunidades, pois não há estudos científicos para balizar o estabelecimento de parâmetros técnicos. Como resultado, os recursos pesqueiros ficaram desprotegidos e as comunidades foram penalizadas.

Sistema de gestão

Os acordos de pesca são instituídos em função dos problemas enfrentados por uma ou várias comunidades. Normalmente esses acordos são determinados pelo risco de escassez de alimentos ou pelo fato já consumado, devido à exploração predatória dos recursos pesqueiros; pelo uso de apetrechos com alta capacidade de captura, como redes com malhas pequenas; pela pesca no período da desova; pela entrada de pescadores estranhos às comunidades e pela captura de pescado com tamanho inferior ao permitido para exploração comercial.

O primeiro passo para a elaboração de um acordo de pesca consiste em identificar o principal problema ou os problemas mais graves. Este trabalho normalmente é realizado por um grupo pequeno, envolvendo diretamente os moradores interessados no estabelecimento do acordo.

Quando o problema provoca tensões entre os moradores, entre comunidades ou mesmo entre moradores e pescadores de fora, inicialmente são identificadas as pessoas envolvidas. Isso permite encontrar a raiz e a abrangência do problema a partir da identificação dos atores-chave. As comunidades têm interesse em saber quem agencia ou apoia alguma atividade considerada danosa, qual a sua abrangência ou se tende a agravar-se ao longo do tempo.

Antes de iniciar o processo de elaboração das normas, o grupo produz coletivamente um mapa baseado na cartografia social dos diferentes ambientes naturais usados para a pesca pelas famílias, localizando os principais usuários desses ambientes para depois convidá-los para as reuniões. Uma vez identificada essa situação, torna-se impossível estabelecer as normas sem considerar os moradores das comunidades vizinhas.

Quando a solução do problema aponta para a constituição de acordo ou normas para a pesca, são então definidos objetivos claros. Sabe-se que o acordo de pesca não é um fim, mas um meio para alcançar um ou mais objetivos, no entanto, deve-se ter cuidado para evitar que as normas privilegiem determinados grupos e penalizem outros. É importante que todos os interesses e ideias estejam contidos no acordo, como forma de garantir o seu cumprimento em longo prazo. 
Contudo, isso não significa que os acordos devam conter muitas normas. Ao contrário, a exemplo dos acordos formulados pelas comunidades dos rios Coati e Cupari, com três proibições: pesca com malhadeira, uso de timbó e matança de pato do mato, e assim conseguiram manter o controle das atividades de extração por mais de 40 anos. Porém, quando o acordo foi reformulado com o assessoramento de agentes externos e incluíram mais de 40 artigos, não houve efeitos práticos. O Quadro 1 traz o resumo da situação dos acordos de pesca em Porto de Moz.

Quadro 1. Situação geral da gestão coletiva dos recursos pesqueiros em Porto de Moz.

\begin{tabular}{|c|c|c|c|c|}
\hline Rios & Comunidades & $\begin{array}{l}\text { Tipo de } \\
\text { Acordo }\end{array}$ & Situação & Avanços \\
\hline $\begin{array}{l}\text { Coati e } \\
\text { Cupari }\end{array}$ & $\begin{array}{l}\text { Maria de Matias, Vila } \\
\text { Nova Bom Jesus, } \\
\text { Vila Bom Jesus e } \\
\text { São João }\end{array}$ & $\begin{array}{l}\text { Acordo } \\
\text { Comunitário } \\
\text { de Pesca }\end{array}$ & $\begin{array}{l}\text { Acordo não cumprido } \\
\text { por moradores; pesca } \\
\text { com o uso de rede; pesca } \\
\text { do pirarucu no período } \\
\text { do defeso, parecer do } \\
\text { procurador do ICMBio } \\
\text { contrário à normatização } \\
\text { do acordo. }\end{array}$ & $\begin{array}{l}\text { À medida que } \\
\text { o ICMBio } \\
\text { desconsiderou a } \\
\text { proposta do acordo } \\
\text { de pesca, houve } \\
\text { uma desarticulação } \\
\text { generalizada das } \\
\text { normas locais, } \\
\text { resultando no seu } \\
\text { abandono e nas } \\
\text { práticas de pesca } \\
\text { predatória }\end{array}$ \\
\hline Acaí & $\begin{array}{l}\text { Espírito Santo, } \\
\text { N. Sa. Aparecida } \\
\text { e Santa Ana do } \\
\text { Mutuncaia }\end{array}$ & $\begin{array}{l}\text { Acordo } \\
\text { Comunitário } \\
\text { de Pesca }\end{array}$ & $\begin{array}{l}\text { Comunidades têm } \\
\text { controle do acesso aos } \\
\text { recursos pesqueiros pelas } \\
\text { normas estabelecidas } \\
\text { desde } 1993 \text {. }\end{array}$ & $\begin{array}{l}\text { Acordo } \\
\text { regulamentado } \\
\text { por Instrução } \\
\text { Normativa da } \\
\text { Secretaria de } \\
\text { Estado de Pesca e } \\
\text { Aquicultura. }\end{array}$ \\
\hline Jaurucu & $\begin{array}{l}\text { Juçara, } \\
\text { Carmelino e Ariruá }\end{array}$ & $\begin{array}{l}\text { Acordo } \\
\text { Comunitário } \\
\text { de Pesca }\end{array}$ & $\begin{array}{l}\text { Pesca moderada nos } \\
\text { períodos de maior } \\
\text { produção, sobretudo } \\
\text { para subsistência. }\end{array}$ & $\begin{array}{l}\text { Acordo entregue } \\
\text { ao ICMBio, } \\
\text { aguardando o } \\
\text { posicionamento. }\end{array}$ \\
\hline Uiui & $\begin{array}{l}\text { Cuieiras, Monte } \\
\text { Sinai e Santa Luzia }\end{array}$ & $\begin{array}{l}\text { Acordo } \\
\text { Comunitário } \\
\text { de Pesca }\end{array}$ & $\begin{array}{l}\text { Controle da pesca do } \\
\text { acari. As comunidades } \\
\text { respeitam os períodos } \\
\text { estabelecidos para a } \\
\text { captura comercial e } \\
\text { utilizam apetrechos } \\
\text { de acordo com o nas } \\
\text { normas estabelecidas. }\end{array}$ & $\begin{array}{l}\text { Doze anos de } \\
\text { acordos com } \\
\text { resultados no } \\
\text { repovoamento do } \\
\text { rio, principalmente } \\
\text { com acari. } \\
\text { Acordo entregue } \\
\text { ao IBAMA, } \\
\text { mas ainda sem } \\
\text { posicionamento } \\
\text { sobre a } \\
\text { regulamentação. }\end{array}$ \\
\hline
\end{tabular}




\begin{tabular}{|l|l|l|l|l|}
\hline Majari & $\begin{array}{l}\text { Espírito Santo e São } \\
\text { João }\end{array}$ & $\begin{array}{l}\text { Plano de uso } \\
\text { do PAEX }\end{array}$ & $\begin{array}{l}\text { Acordo frágil, com } \\
\text { descumprimento das } \\
\text { normas por parte das } \\
\text { famílias locais que } \\
\text { pescam comercialmente. }\end{array}$ & $\begin{array}{l}\text { Conseguiram fazer } \\
\text { reuniões para } \\
\text { decidir as normas } \\
\text { do acordo, mas a } \\
\text { implantação ainda é } \\
\text { um desafio. }\end{array}$ \\
\hline Acaraí & $\begin{array}{l}\text { Por Ti Meu Deus, } \\
\text { Pedreira e Arimum }\end{array}$ & $\begin{array}{l}\text { Acordo de } \\
\text { Convivência }\end{array}$ & $\begin{array}{l}\text { Acordo criado em } \\
\text { 1996, e envolvendo } \\
\text { diferentes recursos dos } \\
\text { rios e floresta. Estão } \\
\text { reformulando o acordo, } \\
\text { analisando os resultados e } \\
\text { definindo novas regras de } \\
\text { convivência. }\end{array}$ & $\begin{array}{l}\text { Conseguiram } \\
\text { manter a } \\
\text { exploração dos } \\
\text { recursos de } \\
\text { maneira estável, } \\
\text { sem gerar conflitos } \\
\text { ou exploração } \\
\text { predatória. }\end{array}$ \\
\hline Peituru & $\begin{array}{l}\text { Miritizal, } \\
\text { Laranjal e Cajueiro }\end{array}$ & $\begin{array}{l}\text { Acordo de } \\
\text { Pesca }\end{array}$ & $\begin{array}{l}\text { Os pescadores locais } \\
\text { estão cumprindo o } \\
\text { acordo, com resultados } \\
\text { positivos no aumento da } \\
\text { quantidade de pescado. } \\
\text { Contudo, há invasão de } \\
\text { pescadores estranhos às } \\
\text { comunidades }\end{array}$ & $\begin{array}{l}\text { As comunidades } \\
\text { conseguiram } \\
\text { pactuar normas } \\
\text { gerais para o } \\
\text { controle da pesca } \\
\text { e mantêm a } \\
\text { gestão do acordo } \\
\text { baseada no diálogo } \\
\text { entre pescadores } \\
\text { externos e internos. }\end{array}$ \\
\hline
\end{tabular}

\section{Papel do Estado}

Para a gestão pesqueira, as populações têm experiências dos acordos de pesca estabelecidos localmente. Como forma de assegurar o cumprimento desses acordos, particularmente por pescadores externos, é fundamental o reconhecimento dos órgãos ambientais, para fortalecer os acordos e amparar as comunidades na eventual gestão de conflitos. Não obstante, o ICMBio considera que têm atribuição exclusiva para elaborar normas de manejo dos componentes dos ecossistemas nas UCs, e não reconhece os acordos de pesca das comunidades, comprometendo a forma tradicional de gestão dos recursos pesqueiros.

Todos os acordos no Brasil têm sido regulamentados por atos administrativos, tais como Instruções Normativas (IN) e Portarias. A publicação do acordo é feita pelo órgão responsável pela gestão das áreas onde as comunidades estão localizadas, no caso da Resex estudada, o ICMBio. A principal demanda das comunidades é o reconhecimento dos acordos existentes pelo órgão gestor reconheça, como forma de fortalecê-los. 


\section{DISCUSSÃO}

Atualmente, um dos maiores desafios para promover o desenvolvimento sustentável na Amazônia é a inclusão produtiva das populações locais, em particular daquelas que vivem em Unidades de Conservação de uso sustentável (UCs), como as Reservas Extrativistas (Resex). Embora haja evidências da capacidade das comunidades para a governança de recursos naturais (MEDINA, 2012; OSTROM, 1999), as comunidades necessitam do apoio do Estado para legitimar os seus sistemas produtivos tradicionais (BATISTA; SIMONIAN, 2013).

No entanto, o Estado, representado pelo ICMBio, tem caracterizado a sua atuação pela ideologia desenvolvimentista, promovida pelo controle da vida das comunidades e da pouca abertura para implantar os sistemas de autogestão dos recursos existentes (PROST; SANTOS, 2016). A Resex é concebida como um "culto" ao extrativismo, e exclui quaisquer possibilidades de mudanças que permitam desenvolver uma produção de base agrícola (HOMMA; SANTOS, 2015), como também não há o reconhecimento dos sistemas tradicionais (MEDINA; BARBOSA, 2015). Mesmo sendo atividades produtivas tradicionais, essas práticas são desestimuladas quando não estão previstas em lei ou não seguem as normas estabelecidas pelo órgão gestor.

O artigo revela um conflito de legitimidade, visto que não há clareza sobre quem tem a atribuição de promover o desenvolvimento para as Resex: se são os moradores, o órgão gestor ou mesmo os pesquisadores/cientistas/ legisladores. Outros estudos têm apontado percepções diferenciadas sobre a noção de desenvolvimento sustentável das populações locais e dos atores externos (MENDONÇA; AQUINO, 2014) e a desigualdade da correlação de forças, em prejuízo das comunidades (BATISTA; SIMONIAN, 2013). Em muitos casos isso tem resultado em conflitos e frustrações das comunidades locais, comprometendo o desenvolvimento local nas UC (PARENTE; BURSZTYN, 2012). No caso da Resex Verde para Sempre, os impasses têm condenado as famílias à pobreza, à ilegalidade e ao êxodo rural (HOMMA; SANTOS, 2015).

A discussão acerca da inclusão produtiva como condição para o desenvolvimento econômico, social e cultural nas unidades de conservação na Amazônia inclui o reconhecimento das práticas locais de gestão dos recursos naturais (MEDINA, 2012). A inclusão produtiva deve ser imediata, para aproveitar a esta oportunidade que pode ser perdida em curto espaço de tempo. Caso permaneça por mais uma década sem um projeto sólido voltado à inclusão produtiva e ao desenvolvimento local, o êxodo rural e a desestruturação das 
cadeias produtivas podem inviabilizar qualquer tentativa posterior. No caso da criação tradicional de bubalinos em Porto de Moz, por exemplo, a suspensão do crédito rural após a criação da Resex deixou as famílias sem condições de manter os investimentos mínimos necessários para superar os desafios das cheias na região.

A inclusão produtiva dos agricultores familiares deve começar pela valorização das atividades e faz formas de produção existentes. As propostas externas direcionadas para a produção familiar na Amazônia até então ou ficaram restritas a áreas demonstrativas subsidiadas ou não conseguiram gerar resultados satisfatórios que atendessem à demanda dessas populações (MEDINA; POKORNY, 2011). O exemplo mais expressivo da disfuncionalidade das propostas externas para a Amazônia vem do modelo de manejo florestal comunitário, que conta com poucas experiências em curso, e nenhuma delas com viabilidade financeira (MEDIN; POKORNY, 2011). Os modelos tecnicistas são formulados sem considerar as práticas, os interesses e a capacidade produtiva das populações locais. A alternativa de governança florestal apresentada pelas comunidades dentro dos parâmetros das suas condições tem grande potencial, cabendo e cabe ao governo reconsiderar a sua concepção de manejo florestal, no intuito de apoiar as iniciativas locais.

O Estado tem, sim, um papel fundamental na promoção do desenvolvimento local com capacidade emancipatória (PROST; SANTOS, 2016). Quando não há o reconhecimento do Estado os sistemas de gestão locais ficam fragilizados diante das ameaças externas, principalmente a invasão de madeireiros, geleiras e grandes produtores. Cabe ao Estado legitimar e apoiar essas propostas, de forma a garantir-lhes a robustez e o respaldo necessários. Considerando todas as limitações do Estado, particularmente dos órgãos ambientais que atuam na região, como a falta de recursos, de pessoal, de infraestrutura e de conhecimento da realidade local (OLIVEIRA, 2015), a estratégia de estabelecer parcerias com as comunidades, em substituição à abordagem atual de comando e controle, pode ser muito promissora. No caso dos acordos de pesca em Porto de Moz, ao regulamentar o acordo do Rio Acaí, a Secretaria de Estado de Pesca e Aquicultura do Pará (Sepaq) fortaleceu as comunidades rurais e promoveu a gestão local dos recursos. Por outro lado, quando o Instituto Chico Mendes de Conservação da Biodiversidade (ICMBio) não reconheceu os acordos de pesca dos rios Coati e Cupari, os recursos pesqueiros ficaram desprotegidos e as comunidades foram penalizadas. 


\section{CONCLUSÃO}

Os resultados revelam que os principais sistemas produtivos desenvolvidos pelas comunidades da Resex Verde para Sempre estão ameaçados pela burocracia dos órgãos governamentais: a criação de búfalos foi proibida, pelo fato de não constar nas normas do SNUC, mesmo sendo uma atividade tradicional anterior à criação da Resex; o uso dos recursos naturais não é reconhecido pelo governo, pois exige aprovação de planos formais de manejo florestal como a única condição para o uso comercial dos produtos florestais, porém os planos contêm requisitos inacessíveis para as comunidades; finalmente, o ICMBio não reconhece os acordos de pesca elaborados pelas comunidades pelo fato de ainda não ter o plano de manejo da reserva, entretanto, esses acordos têm assegurado, continuamente, os estoques pesqueiros para a alimentação das famílias.

O estudo de caso da Resex Verde para Sempre sugere que o desenvolvimento sustentável nas unidades de conservação requer necessariamente o(a):

Entendimento da inclusão produtiva como alternativa viável de desenvolvimento rural sustentável;

Apoio às experiências locais de produção agrícola, pecuária e extrativista que têm maior potencial de sucesso em relação aos modelos produtivos externos;

Entendimento de que o Estado tem um papel fundamental no reconhecimento e apoio às práticas produtivas locais, e deve ser receptivo a novas parcerias com as comunidades, superando a conduta atual baseada no comando e controle.

A pobreza e o êxodo das famílias da Resex Verde para Sempre revelam a necessidade de soluções imediatas para a questão produtiva nas Reservas Extrativistas. A inclusão produtiva alcançará maior sucesso no incremento dos sistemas tradicionais de criação de animais, gestão florestal e manejo de pesca do que de soluções externas, como bolsa floresta ou planos de manejo tecnicistas. $\mathrm{O}$ não reconhecimento dos sistemas de governança local (como no caso dos acordos de pesca) fragiliza esses sistemas e desmobiliza as comunidades, comprometendo a conservação dos recursos naturais.

\section{REFERÊNCIAS}

ALEGRETTTI, M. A construção social de políticas públicas: Chico Mendes e o movimento dos seringueiros. Desenvolvimento e Meio Ambiente, n. 18, p. 39-59,2008. 
BATISTA,I.; SIMONIAN,L.Implicações políticas, econômicas e socioambientais da Resex Mãe Grande de Curuçá: perspectivas de desenvolvimento sustentável no estuário paraense. Novos Cadernos NAEA, v.16, n. 1, p. 203-220, 2013.

BRASIL. Lei no. 9.985, de 18 de julho de 2000. Regulamenta o art. 225, J 1o, incisos I, II, III e VII da Constituição Federal, institui o Sistema Nacional de Unidades de Conservação da Natureza e dá outras providências. Diário Oficial da União, Brasília, DF, 19 jul., 2000. Disponível em: <http://www.planalto.gov. br/ccivil_03/LEIS/L9985.htm>. Acesso em: 10 nov. 2006.

DOVE, M. A revisionist view of tropicaldeforestation \& development. Environmental Conservation, v. 20, n.1, p.17-55. 1993.

GONÇALVES, C. Amazônia, Amazônias. 3. ed. São Paulo: Contexto, 2012.

HOMMA, A.; SANTOS, J. O desafio atual das Reservas Extrativistas: agricultura ou extrativismo? In: MEDINA, G.; BARBOSA, C. Experiências produtivas de agricultores familiares da Amazônia. Goiânia: Kelps, 2015. 198p.

MEDINA, G.; BARBOSA, C. Experiências produtivas de agricultores familiares da Amazônia. Goiânia: Kelps, 2015. 198p.

MEDINA, G.; POKORNY, B. Avaliação financeira do Manejo Florestal Comunitário. Novos Cadernos NAEA, v.14, p. 25-36. 2011.

MEDINA, G. Governança local para manejo florestal na Amazônia. Revista Brasileira de Ciências Sociais, v.27, n.78, p. 65-191. 2012.

MENDONÇA, M.; AQUINO, M. Ações e percepções de desenvolvimento sustentável na emergência de territórios na Amazônia Brasileira. Novos Cadernos NAEA, v. 17, n. 2., p. 219-238. 2014.

MUÑOZ, I.; PAREDES, M.; THORP, R. Group inequalities and the nature and power of collective action: case studies from Peru. World Development, v. 35, n. 11, p. 1929-1946, 2007.

OLIVEIRA, M. Capacidade estatal e implementação de política de desenvolvimento regional sustentável na Amazônia. Novos Cadernos NAEA, v.18, n. 3, p. 271-291, 2015.

OSTROM, E. Self-governance \& forest resources. Bogor: Cifor, 1999. (Occasional Paper, n. 20).

PARENTE, I.; BURSZTYN, M. Conflitos em Unidades de Conservação na Amazônia: o caso do Parque Estadual Monte Alegre-Pará. Novos Cadernos NAEA, v.15, n. 2, p. 21-44, 2012. 
POKORNY, B.; GODAR, J.; HOCH, L.; JOHNSON, J.; KONING, J.; MEDINA, G.; WEIGELT, J. A Produção familiar como alternativa de desenvolvimento sustentável para a Amazônia. 1. ed. Bogor: Cifor, 2010. 175p.

PROST, C.; SANTOS, M. Gestão territorial em Unidades de Conservação de Uso Sustentável e incoerências no SNUC. Novos Cadernos NAEA, v.19, n.1, p. 143-158, 2016. 